Research Paper:

\title{
The Role of Self-compassion and Hope in the Relationship Between Psychological Wellbeing, Maladaptive Schemas, Resilience, and Social Support in Women With Multiple Sclerosis
}

Seyedeh Fatemeh Hassani ${ }^{1}$ (D), Taher Tizdast ${ }^{1 *}$ (D), Mohammad Reza Zarbakhsh ${ }^{1}$

1. Department of Psychology, Tonekabon Branch, Islamic Azad University, Tonekabon, Iran

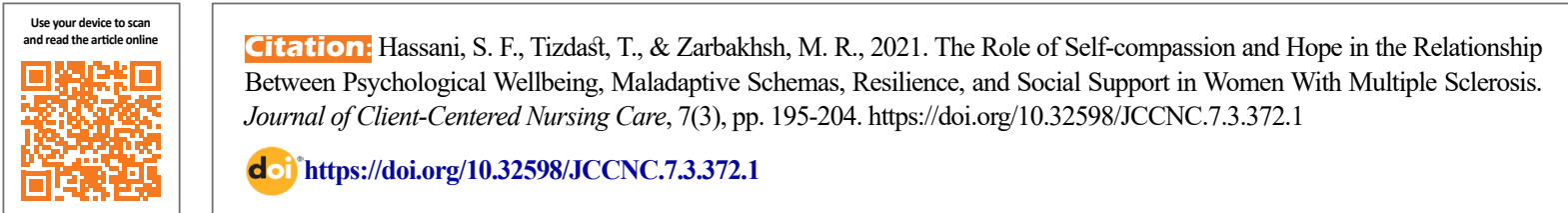

(c) (i) (8)

Article info:

Received: 23 Apr 2021

Accepted: 11 Jun 2021

Published: 01 Aug 2021

Keywords:

Empathy, Multiple sclerosis, Psychological resilience, Schemas, Social support, Women

\begin{abstract}
A B S T RA C T
Background: Psychological disorders often threaten the mental health of individuals with Multiple Sclerosis (MS). Higher levels of psychological wellbeing and life satisfaction provide these patients with better social relationships and greater biopsychological health. The present study aimed to investigate the relationship between psychological wellbeing, early maladaptive schemas, resilience and perceived social support mediated by self-compassion and hope in women with MS.
\end{abstract}

Methods: This descriptive-correlational study was conducted from August to October 2019. The study population consisted of all female patients with MS who were admitted to Imam Khomeini Hospital Complex, Milad Hospital, and Charity Foundation for Special Diseases in Tehran City, Iran. Using the stratification convenience sampling method, 300 patients were recruited as the study sample. The research instruments included the Self-Compassion Scale, Early Maladaptive Schema Questionnaire-Short Form, the Connor-Davidson Resilience Scale, the Multidimensional Perceived Social Support Scale, Ryff's Scale of Psychological Wellbeing, and the Adult Hope Scale. The collected data were analyzed by structural equation modeling. SPSS and AMOS were used for analyzing the collected data.

Results: There was a positive and significant relationship between self-compassion, hope, resilience, perceived social support, and psychological wellbeing $(\mathrm{P}<0.01)$. There was also a negative relationship between early maladaptive schemas and psychological wellbeing in the study participants $(\mathrm{P}<0.01)$. The indirect path analysis data indicated that self-compassion and hope played a mediating role in the relationship between perceived social support, resilience, early maladaptive schemas, and psychological wellbeing $(\mathrm{P}<0.01)$.

Conclusion: The designed model fitted the empirical data very well. Therefore, the research components can help researchers, therapists, and psychiatric nurses to design better procedures to care for patients with MS.

* Corresponding Author:

Taher Tizdast

Address: Department of Psychology, Tonekabon Branch, Islamic Azad University, Tonekabon, Iran.

Tel: +98 (11) 54271105

E-mail: tizdasit@gmail.com 


\section{Highlights}

- Early maladaptive schemas presented a negative effect on psychological wellbeing in the examined women with multiple sclerosis.

- There was a positive and significant relationship between resilience, perceived social support, hope, self-compassion, and psychological wellbeing in the study subjects.

- Self-Compassion and hope played a mediating role in the relationship between resilience, early maladaptive schemas, and psychological wellbeing in the studied women with multiple sclerosis.

\section{Plain Language Summary}

Chronic diseases can cause extreme psychological stress, which can, in turn, lead to serious psychosocial disorders. Patients with such diseases are prone to family disruption. The chronic pain of the disease, concerns about the future of family members, fear of death, treatment complications, decreased performance, impaired mental image, and sexual problems can impair the mental health of these patients. This study has suggested the following conclusions: early maladaptive schemas, resilience, perceived social support, self-compassion, and hope directly affected psychological wellbeing in patients with MS. Self-Compassion and hope played a mediating role in the relationship between perceived social support, resilience, early maladaptive schemas, and psychological wellbeing.

\section{Introduction}

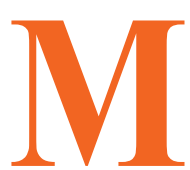

ultiple Sclerosis (MS) is an inflammatory, chronic, and autoimmune disease, i.e., associated with the destruction of the myelin sheath in the central nervous system (Patten 2020). MS development is attributed to a combination of genetic and environmental factors (Alhussain et al. 2020). The epidemiology of MS has changed in recent decades; numerous reports are released every day on the increasing prevalence of the disease worldwide. An estimated 2.5 million individuals develop MS worldwide (Schmidt \& Jöstingmeyer 2019). The MS prevalence in Iran is 101.39 per 100000 inhabitants with 134.03 for women and 42.45 for men (Eskandarieh et al. 2017).

MS symptoms not only restrict an individual's general health but also affect their ability to perform daily physical activities. Balance plays a vital role in daily activities, and reduced physical control reduces personal stability; thus, it decreases functional independence, exacerbates disability, and increases the risk of falling (Ilett et al. 2016, Seyedoshohadaee et al. 2016). All these factors substantially influence Psychological Wellbeing (PW) in patients with MS. These factors are also closely related to the development of mental disorders. High fatigue levels reduce the Quality of Life (QoL) and PW of these patients (Mirhosseini et al. 2019, Veauthier \& Paul, 2014). PW is a component of QoL that refers to the way individuals evaluate their lives. It consists of cognitive and affective dimensions. The cognitive dimension refers to individuals' cognitive assessments of their life satisfaction, while the affective dimension indicates having maximum positive and minimum negative emotions (Maguire \& Maguire 2020).

Early Maladaptive Schemas (EMSs) are associated with PW in individuals; EMSs act on the deepest levels of cognition and the core of an individual's personality. These schemas play an essential role in the mental health and QoL of individuals with chronic diseases (Schaap et al. 2016). EMSs refer to dysfunctional cognitive frameworks for viewing the self and others. They mainly emerge in response to adverse childhood events and develop over time. These deep and pervasive patterns or themes of memories, emotions, physical sensations, and cognitions are interwoven with the destructive aspects of childhood experiences. EMSs are systematically repeated throughout life in the form of special patterns (Moghadam et al. 2021). There is a significant relationship between EMSs and PW (Hashemipoor et al.2019).

Resilience is another characteristic associated with PW (Foster et al. 2020). Resilient individuals experience positive affective and cognitive events; enjoy high levels of self-esteem and social functioning, and withstand the negative consequences of unfortunate life events. Resilience is a return to equilibrium or the ability to bounce back under threatening conditions; therefore, it 
facilitates adaptation to life (Pettit et al. 2019). In general, resilience refers to the ability to successfully adapt to challenging and threatening conditions and to develop competency under difficult conditions (Seiler \& Jenewein 2019). Resilience goes beyond recovery from disturbances. It can be described as positive growth or adjustment after periods of imbalance. Resilience enables man to overcome life stressors (Duchek 2020). Resilient individuals adapt to tough environments and withstand different stressors; thus, resilience is considered some kind of positive growth (Meyer 2019). Wu et al. (2020) stated that resilience directly predicts PW in students. Additionally, (Rutten et al. 2013) found a significant relationship between resilience and PW.

As an emotion-focused coping strategy, social support can potentially influence PW. Social support indicates how much love, attention, and support an individual receives from their family members, friends, and others (Lee \& Giuliani 2019). Social support increases confidence to try new subjects and improves life satisfaction. It also increases survival rates and improves PW in individuals (Wong et al. 2014). However, perceiving support is much more critical than receiving it. In other words, a patient's perception of the support he/she receives is more important than the level of support provided to him/her (Wong et al. 2014). Not all relationships with others are considered social support. In other words, relationships are not sources of social support, unless one perceives them as available and effective sources that meet their needs. Sometimes the support offered to a subject is untimely, ineffective, or against the individual's will; therefore, a subject's perception of support is more crucial than the support (Thoits 2020). High perceived social support can prevent adverse physiological effects of diseases, increase self-care and self-confidence, and positively affect biopsychosocial conditions in individuals. It can also improve performance and interpersonal relationships (Wongpakaran et al. 2011).

Studies suggested that self-compassion is another crucial factor affecting mental health and wellbeing (Shahbazi et al. 2020). According to Neff (2003), self-compassion consists of the component of self-kindness versus self-judgment, common humanity versus isolation, and mindfulness versus over-identification. The combination of these components reveals how compassionately an individual treats self. Self-Compassionate individuals understand themselves instead of judging themselves and support themselves to eliminate their shortcomings. Research suggests that self-kindness, common humanity, and mindfulness are negatively related to feelings of isolation. Demonstrating compassion for oneself and others is regarded as an effective strategy for improving health and prosperity (Homan \& Sirois 2017). Self-Compassionate individuals experience greater mental health, compared to those with lower self-compassion levels. This is because self-condemnation, isolation, and overidentification of thoughts and feelings intensify the experience of pain and failure. Moreover, self-compassionate individuals attempt to avoid experiencing pain; subsequently, it activates their coping mechanisms to maintain and improve mental health (Bluth \& Blanton 2015).

Individuals with MS report higher levels of psychological distress than the healthy population. Therefore, protective factors, like hope can play a crucial role in coping with disease-related crises (Bambara et al. 2014). Hope is a psychological trait, i.e., essential for life satisfaction. Hope facilitates the adaptation of a patient to difficult conditions, especially during periods of pain and deprivation (Kratz et al. 2014). Given the above discussion, a deeper understanding of the relationships of psychological characteristics and PW seems to help women with MS better adapt themselves to their new living conditions. Accordingly, this study aimed to investigate the relationship between PW, early maladaptive schemas, resilience, and perceived social support, mediated by self-compassion and hope in women with MS.

\section{Materials and Methods}

The present descriptive-correlational study was conducted from August to October 2019. The study population consisted of all women with MS who were admitted to Imam Khomeini Hospital Complex, Milad Hospital, and Charity Foundation for Special Diseases in Tehran City, Iran. Using the stratification convenience sampling method, 300 women were selected as the research sample. Depending on the type of study and the number of predictor variables in structural equation analysis, the sample size should be at least 10 times higher than the number of variables plus 50 (Tabachnick \& Fidell 2007). In the present study, there was a total of 23 observed variables $(23 \times 10+50=280)$. Therefore, at least 280 samples were required. In this study, to reduce sampling error, 300 subjects were considered as the research sample. The inclusion criteria were consent to participate in the study, the age range of 40-60 years, having a minimum of secondary education, $\geq 6$ months have passed since the diagnosis of MS, and having no mental disorders. The exclusion criterion was providing incomplete questionnaires. 
The following tools were used in the present study to collect the necessary data:

Ryff's Scale of Psychological Wellbeing: This scale was developed by Ryff in 1989. The 84-item scale measures the dimensions of the 6-factor model of PW, including positive relations with others, autonomy, environmental mastery, personal growth, purpose in life, and self-acceptance. The items are scored on a 6-point Likert-type scale. Besides, the total score ranges from 84 to 504, with higher scores indicating better PW. The cutoff point of the scale equals 252 . In this study, the score of the whole scale was considered. (Bayani, Mohammad Koochekya \& Bayani 2008) reported a Cronbach's alpha coefficient of 0.82 for the whole Persian version of the scale. In this study, Cronbach's alpha coefficient was measured as 0.79 .

Early Maladaptive Schema Questionnaire-Short Form: This 75-item questionnaire was developed by Young in 1988 to assess 15 EMSs, including emotional deprivation, rejection/abandonment, mistrust/abuse, social isolation, defectiveness/shame, failure, impaired autonomy/ incompetence, vulnerability to harm or illness, enmeshment, subjugation, self-sacrifice, emotional inhibition, unrelenting standards, entitlement, and insufficient selfcontrol. The questionnaire is scored based on a 6-point Likert-type scale (from $1=$ completely false to $6=\mathrm{com}$ pletely true). The minimum and maximum obtainable scores on this questionnaire are 75 and 450, respectively. In this questionnaire, the total score was considered. Divandari (2009) reported a Cronbach's alpha coefficient of 0.87 for the Persian version of the questionnaire. In the present study, Cronbach's alpha coefficient was calculated as 0.78 for the whole questionnaire.

The Connor-Davidson Resilience Scale: This scale was designed by Connor and Davidson in 2003 to measure resilience. It consists of 25 items scored based on a 5 -point Likert-type scale (ranging from $0=$ not true to $4=$ nearly true). The minimum and maximum obtainable scores on this questionnaire are 0 and 100 , respectively. The higher scores indicate higher resilience (Connor \& Davidson 2003). Badie et al. (2020) reported a Cronbach's alpha coefficient of 0.85 for the Persian version of the questionnaire. In the present study, Cronbach's alpha coefficient was computed as 0.81 .

Neff's Self-Compassion Scale: This 26-item self-report scale was designed by Neff in 2003 to measure selfcompassion levels. The 6 subscales of this tool (i.e., selfkindness, self-judgment, common humanity, isolation, mindfulness, and over-identification) measure the qual- ity of individuals' relationships with their experiences. The items are scored on a 5-point Likert-type scale, ranging from almost never (score 1) to almost always (score $4)$. The higher scores indicate higher self-compassion (Neff 2003). In this study, the total score was considered, ranging from 26 to 104. Momeni et al. (2014) reported a Cronbach's alpha coefficient of 0.89 for the Persian version of the scale. In the present study, Cronbach's alpha coefficient was measured to be 0.83 .

The Multidimensional Perceived Social Support Scale: This questionnaire was developed by Zimet in 1988 . The 12-item multidimensional scale measures Perceived Social Support (PSS) provided by family, friends, and significant others. A 7-point Likert-type scale is used to score items from strongly disagree to strongly agree. The total score is calculated by adding the scores given to all items (total score range: 12-84). Higher scores indicate greater PSS and vice versa. The cut-off point of the scale equals 48 (Zimet et al. 1988). Savari et al. (2021) reported a Cronbach's alpha coefficient of 0.85 for the Persian version of the scale. In the present study, Cronbach's alpha coefficient was calculated as 0.89 .

The Adult Hope Scale: This self-report scale was developed by Snyder in 1996 to measure the state and trait dimensions of hope. It has 12 items; of which, 8 items are used in the scale and the other 4 items are used to develop a lie scale. Items $2,9,10$, and 12 measure factor thinking, while items $1,4,6$, and 8 measure strategic thinking. The items are scored on a 4-point Likert-type scale, ranging from 1 to 4 . The total score is calculated by adding the scores given to all items (Total score range: 8-32). Higher scores indicate greater hope and vice versa (Snyder et al. 1996). Beigi et al. (2011) reported a Cronbach's alpha coefficient of 0.75 for the Persian version of the scale. In the present study, Cronbach's alpha coefficient was computed to be 0.82 .

The obtained data were analyzed by descriptive and inferential statistics, such as mean, standard deviation, and Pearson correlation coefficient. The path analysis was used to assess the proposed model. SPSS and AMOS were used for analyzing the achieved data.

\section{Results}

The study subjects included 300 women with MS in the age range of 40-60 years. The Mean \pm SD age and duration of MS were $47.25 \pm 6.82$ and $6.72 \pm 2.11$ years, respectively. The descriptive statistics, such as mean, $\mathrm{SD}$, skewness, and kurtosis of the research variables are presented in Table 1. According to Table 1, the kurtosis 
Table 1. Mean $\pm S D$, skewness, and kurtosis of the research variables

\begin{tabular}{cccc}
\hline Variables & Mean \pm SD & Skewness & Kurtosis \\
\hline Hope & $21.54 \pm 6.32$ & -0.52 & -0.16 \\
Resilience & $84.71 \pm 31.12$ & 0.95 & -0.33 \\
\hline Perceived social support & $36.48 \pm 8.63$ & 0.86 & -0.38 \\
\hline Early maladaptive schemas & $234.78 \pm 58.34$ & 0.49 & -1.19 \\
\hline Self-compassion & $53.99 \pm 11.85$ & -0.11 & -0.47 \\
\hline Psychological wellbeing & $138.08 \pm 40.05$ & -0.69 & -0.12 \\
\hline
\end{tabular}

and skewness statistics of the research variables ranged from -1 to 1 ; thus, the normality of data distribution was approved. The proposed model of the mediating role of hope and self-compassion in the relationship of resilience, early maladaptive schemas, perceived social support, and PW is illustrated in Figure 1. According to Table 2, the Root Mean Square Error of Approximation $(\mathrm{RMSEA}=0.04)$ indicates a good fit of the model.

According to Table 3, EMSs $(\beta=-0.70, \mathrm{t}=-6.29)$, resilience $(\beta=0.19, \mathrm{t}=2.89)$, PSS $(\beta=0.28, \mathrm{t}=3.40)$, selfcompassion $(\beta=0.75, \mathrm{t}=8.71)$, and hope $(\beta=0.53, \mathrm{t}=5.62)$ directly affected PW in the study subjects. Therefore, the hypothesis related to the direct effect of EMSs, resilience, PSS, self-compassion, and hope was supported on $\mathrm{PW}$ in women with MS $(\mathrm{P}<0.01)$.
As per Table 4, the hypothesis related to the indirect effect of resilience was also confirmed on PW in women with MS through hope $(\mathrm{P}<0.01)$. Additionally, the indirect effect of PSS was also confirmed on PW in women with MS through self-compassion and hope $(\mathrm{P}<0.01)$.

\section{Discussion}

The present study aimed to investigate the relationship between PW, EMSs, resilience, and PSS, mediated by self-compassion and hope in women with MS, in Tehran City, Iran. The variables of EMSs, resilience, and PSS, as exogenous variables, and self-compassion and hope", as mediating variables, had significant direct and indirect effects on PW, respectively. The obtained results suggested that the research model fits the data well. Moreover, EMSs presented significant direct and indirect

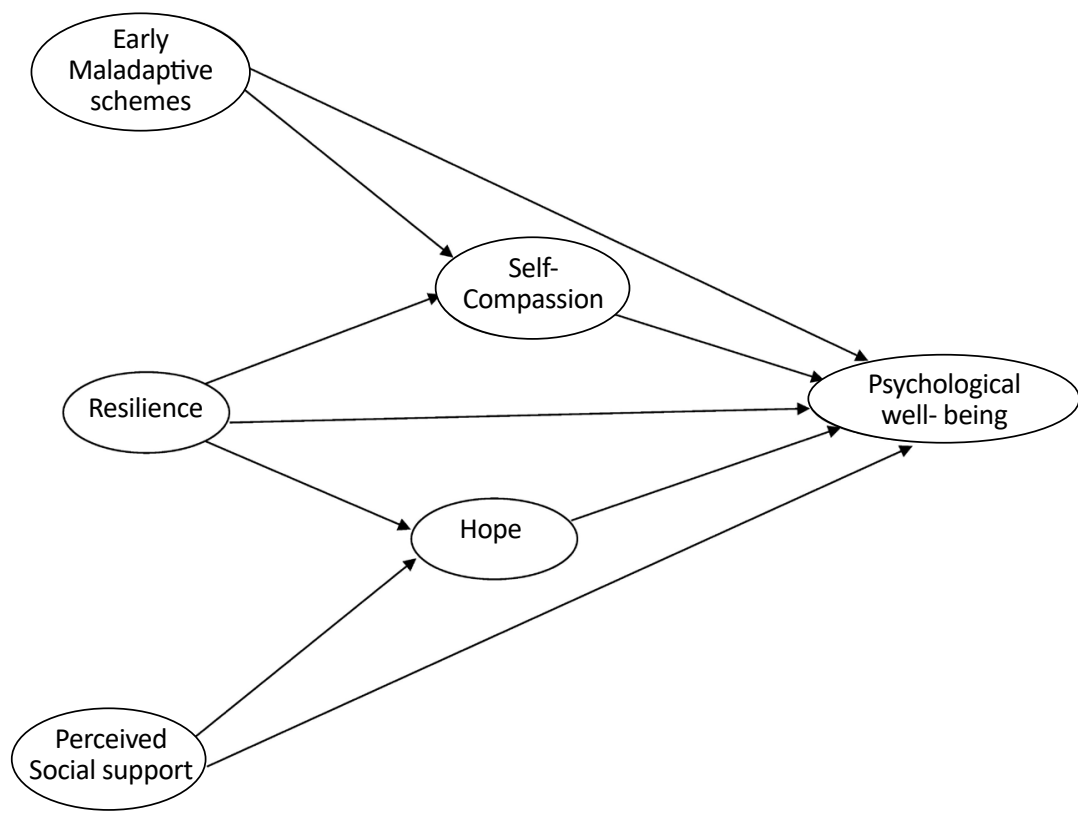

Client- Centered Nursing Care

Figure 1. The proposed model of the mediating role of hope and self-compassion in the relationship between resilience, early maladaptive schemas, perceived social support, and psychological well-being 
Table 2. The fit indicators of the model

\begin{tabular}{ccccccc}
\hline Fit Indicators & $\left(\boldsymbol{\chi}^{2} / \mathbf{d f}\right)$ & CFI & NLI & GFI & AGFI & RMSEA \\
\hline Proposed model & 1.38 & 0.97 & 0.94 & 0.97 & 0.95 & 0.04 \\
\hline & & & & & \multicolumn{2}{c}{ Client- Centered Nursing Care }
\end{tabular}

Table 3. Direct effects between research variables in the proposed model

\begin{tabular}{ccccc}
\hline Predictors & Criterion & $\boldsymbol{\beta}$ & $\mathbf{t}$ & $\mathbf{P}$ \\
\hline Early maladaptive schemas & Psychological wellbeing & -0.70 & -6.29 & 0.001 \\
Resilience & Psychological wellbeing & 0.19 & 2.89 & 0.005 \\
\hline Perceived social support & Psychological wellbeing & 0.28 & 3.40 & 0.001 \\
\hline Self-Compassion & Psychological wellbeing & 0.75 & 8.71 & 0.001 \\
Hope & Psychological wellbeing & 0.53 & 5.62 & 0.001 \\
\hline
\end{tabular}

Client- Centered Nursing Car

Table 4. Indirect and intermediary effects between research variables in the proposed model

\begin{tabular}{|c|c|c|c|c|c|}
\hline Predictor & Mediator & Criterion & $\boldsymbol{\beta}$ & $\mathbf{t}$ & $\mathbf{P}$ \\
\hline Early maladaptive schemas & Self-compassion & Psychological wellbeing & -0.15 & -2.19 & 0.020 \\
\hline Early maladaptive schemas & Hope & Psychological wellbeing & -0.46 & -5.11 & 0.001 \\
\hline Resilience & Self-compassion & Psychological wellbeing & 0.03 & 0.94 & 0.037 \\
\hline Resilience & Hope & Psychological wellbeing & 0.47 & 4.93 & 0.001 \\
\hline Perceived social support & Self-compassion & Psychological wellbeing & 0.27 & 3.88 & 0.001 \\
\hline Perceived social support & Hope & Psychological wellbeing & 0.17 & 3.02 & 0.002 \\
\hline
\end{tabular}

effects on PW. In this regard, (Hashemipoor et al. 2019) argued that maladaptive schemas have negative relationships with psychological disorders, including depression. These negative relationships can be attributed to the meaning that lies in some maladaptive schemas, as well as in the feeling of mastery over the environment and personal value gained in some orientations.

To explain this finding, it should be noted that EMSs are a predictor of decreased self-acceptance. Social isolation/ alienation makes individuals feel that they are different from others; thus, they avoid relationships with others and feel that they do not belong to any community or group. According to Pourpashang and Mousavi (2021), individuals with social isolation/alienation schema also have difficulty accepting themselves. This is because they feel alienated from themselves; therefore, become unaware of their needs and strengths and weaknesses, and not attempt to reconcile with themselves. Furthermore, these individuals refuse to accept others and do not establish sincere relationships with them. Patients with MS tend to easily give up their social activities and become more socially isolated. Isolation is among major problems in patients with MS.

Resilience affected PW both directly and through the variable of hope. Accordingly, Rutten et al. (2013) found a significant positive relationship between resilience and PW. To explain this finding, the nature of resilience should be first assessed. According to Burns and Rosi et al. (2019), increased positive affect and decreased negative affect result in higher levels of self-esteem and greater coping abilities in the face of negative experiences. Besides, the positive characteristics of resilient individuals (e.g., participating in health-promoting behaviors, enjoying challenges, interpreting negative emotions positively, \& using appropriate adaptive strategies) affect their health indicators. The resilience process makes adverse events ineffective; therefore, it is associated with mental health and wellbeing in individuals. According to Rezaei et al. (2018), resilience is the capacity of individuals to change, regardless of the risks involved. 
Tugade et al. (2004) define resilience as one's ability to change adverse outcomes. Furthermore, higher resilience and coping abilities reduce the risk of mental disorders and improve health and wellbeing.

PSS affected PW both directly and through hope and self-compassion. Accordingly, Bright and Stanton (2018) found a significant relationship between social support and depression symptoms. This implies that female cancer patients receiving high levels of social support are less prone to experience depression symptoms. Koch-Gallenkamp et al. (2016) found a significant relationship between social support level and fear of cancer recurrence. In their study, women who received higher levels of social support were less afraid of cancer recurrence than those receiving lower levels of social support. The direct theory indicates that social support directly improves one's health and wellbeing. It also supports the direct relationship between QoL and social support. The lack of social support is stressful; thus, social support is beneficial in stressful and pleasant situations.

Self-Compassion directly impacted PW in the study subjects. A meta-analysis on the association between selfcompassion and psychopathology found that high levels of self-compassion are correlated with low levels of mental disorders and vice versa. Consistent with the present research results, Shahbazi et al. (2020) signified that selfcompassion therapy helps patients gain new experiences; thus, it organizes their alternative and adaptive ideas and beliefs. Self-Compassion also increases the feelings of belonging, safety, and self-efficacy in patients. High levels of self-efficacy increase patients' inner satisfaction levels, which in turn improves their PW. In this regard, Van Dam et al. (2011) investigated the effects of self-compassion on the severity of the symptoms of mental problems. They concluded that self-compassion is a great predictor of mental health, especially depression.

Hope directly affected PW in the study subjects. Accordingly, Nabi et al. (2016) observed a significant positive relationship between hope and PW in patients with diabetes. Schroevers et al. (2011) found that cancer patients who can think about pleasant things, instead of negative experiences of cancer, are healthier than others. Positive focus is an effective approach to reduce the negative effects of diseases and increase positive outcomes. Individuals with lower levels of hope tend to attribute their problems, stresses, and illnesses to permanent factors; thereby, they act passively in the face of problems. Therefore, these individuals make minimal effort to solve their problems or to improve their health. Kleiman et al. (2017) define hope as the tendency to hold the most optimistic view of life with a positive as- sessment and the prediction of the outcome of life events. Therefore, hope creates positive feelings in individuals and increases their satisfaction with various dimensions of life. Besides, these factors in turn result in desirable PW. Moreover, a hopeful subject confidently expects that everything will be fine despite all obstacles and frustrations in life. Therefore, hopeful individuals enjoy higher levels of PW.

\section{Conclusion}

The findings indicated that self-compassion and hope played a mediating role in the relationship between perceived social support, resilience, early maladaptive schemas, and psychological wellbeing. Structural Equation Modeling (SEM), i.e., a non-experimental method, was used to examine the structural relationships between the research variables. In non-experimental methods, some intervening variables (e.g., social class) are not controlled. Applying self-report tools was the main limitation of the present research. The respondents may irresponsibly complete the questionnaires, without being completely honest, or they may not assess themselves accurately. Therefore, researchers are suggested to conduct studies about PW and its antecedents in other populations (e.g., men, patients with diseases other than MS, etc.) to assess and compare the effects of the research variables on PW among different groups. In addition, further qualitative studies must be conducted to identify factors affecting PW in patients with MS.

\section{Ethical Considerations}

\section{Compliance with ethical guidelines}

The Ethics Review Board of Islamic Azad University, Tonekabon Branch, approved the present study (Code: IR.IAU.TON.REC.1399.077). Written consent was sought from all the subjects.

\section{Funding}

This study was extracted from the $\mathrm{PhD}$. dissertation of the first author at the Department of Psychology, Tonekabon Branch, Islamic Azad University, Tonekabon and was not funded by any organization.

\section{Authors' contributions}

Conceptualization, Methodology, writing - original draft, and supervision: Seyedeh Fatemeh Hassani, Taher Tizdast; Investigation, writing - review \& editing: All authors; Investigation: Mohammad Reza Zarbakhsh; Funding acquisition, resources: Seyedeh Fatemeh Hassani. 


\section{Conflict of interest}

The authors declared no conflicts of interest.

\section{References}

Alhussain, H., et al. 2020. Multiple Sclerosis patients in Saudi Arabia: Prevalence of depression and its extent of severity. Cureus, 12(2), p. e7005. [DOI:10.7759/cureus.7005]

Badie, A., et al. 2020. Drug cravings and its relationship with family communication patterns and resiliency through the mediatory role of difficulty in cognitive emotion regulation. Journal of Client-Centered Nursing Care, 6(2), pp. 125-34. [DOI:10.32598/JCCNC.6.2.329.1]

Bambara, J. K., et al. 2014. Social support and depressive symptoms among caregivers of veterans with Multiple Sclerosis. Rehabilitation Psychology, 59(2), pp. 230-5. [DOI:10.1037/ a0036312]

Bayani, A. A., Mohammad Koochekya, A. \& Bayani, A., 2008 [Reliability and validity of Ryff's psychological well-being scales (Persian)]. Iranian Journal of Psychiatry and Clinical Psychology, 14(2), pp. 146-51. http://ijpcp.iums.ac.ir/browse. php?a_id=464\&sid=1\&slc_lang=en

Beigi, A., et al. 2011. [The discriminative role of quality of life and hope in narcotic anonymous and methadone maintenance groups (Persian)]. Journal of Clinical Psychology, 3(3), pp. 75-84. [DOI:10.22075/JCP.2017.2064]

Bluth, K. \& Blanton, P. W., 2015. The influence of self-compassion on emotional well-being among early and older adolescent males and females. The Journal of Positive Psychology, 10(3), pp. 219-30. [DOI:10.1080/17439760.2014.936967]

Bright, E. E. \& Stanton, A. L., 2018. Prospective investigation of social support, coping, and depressive symptoms: A model of adherence to endocrine therapy among women with breast cancer. Journal of Consulting and Clinical Psychology, 86(3), pp. 242-53. [DOI:10.1037/ccp0000272]

Connor, K. M. \& Davidson, J. R., 2003. Development of a new resilience scale: The Connor-Davidson Resilience Scale (CDRISC). Depression and Anxiety, 18(2), pp. 76-82. [DOI:10.1002/ da.10113]

Divandari, H., et al. 2009. [The young Schema Questionnaire - Short Form (SQ-SF): investigation psychometric properties and factor structure between students in Islamic Azad university Kashmar Branch (Persian)]. Scientific Journal of Educational Researches, 5(20), pp. 1-29. http://edu.bojnourdiau.ac.ir/article_518167.html?lang=en

Duchek, S., 2020. Organizational resilience: A capabilitybased conceptualization. Business Research, 13(1), pp. 215-46. [DOI:10.1007/s40685-019-0085-7]

Eskandarieh, S., et al. 2017. Prevalence and incidence of Multiple Sclerosis in Tehran, Iran. Iranian Journal of Public Health, 46(5), pp. 699-704. [PMID][PMCID]

Foster, K., et al. 2020. Workplace stressors, psychological wellbeing, resilience, and caring behaviours of mental health nurses: A descriptive correlational study. International Jour- nal of Mental Health Nursing, 29(1), pp. 56-68. [DOI:10.1111/ inm.12610]

Hashemipoor, F., Jafari, F. \& Zabihi, R., 2019. Maladaptive schemas and psychological well-being in premenopausal and postmenopausal women. Menopause Review, 18(1), pp. 33-8. [DOI:10.5114/pm.2019.84155]

Homan, K. J. \& Sirois, F. M., 2017. Self-compassion and physical health: Exploring the roles of perceived stress and health-promoting behaviors. Health Psychology Open, 4(2), p. 2055102917729542. [DOI:10.1177/2055102917729542]

Ilett, P., et al. 2016. Balance and gait in people with multiple sclerosis: A comparison with healthy controls and the immediate change after an intervention based on the bobath concept. Physiotherapy Research International, 21(2), pp. 91-101. [DOI:10.1002/pri.1624]

Kleiman, E. M., et al. 2017. Optimism and well-being: A prospective multi-method and multi-dimensional examination of optimism as a resilience factor following the occurrence of stressful life events. Cognition E Emotion, 31(2), pp. 269-83. [D OI:10.1080/02699931.2015.1108284]

Koch-Gallenkamp, L., et al. 2016. Fear of recurrence in long-term cancer survivors-Do cancer type, sex, time since diagnosis, and social support matter? Health Psychology, 35(12), pp. 1329-33. [DOI:10.1037/hea0000374]

Kratz, A. L., Ehde, D. M. \& Bombardier, C. H., 2014. Affective mediators of a physical activity intervention for depression in multiple sclerosis. Rehabilitation Psychology, 59(1), pp. 57-67. [DOI:10.1037/a0035287]

Lee, C. H. \& Giuliani, F., 2019. The role of inflammation in depression and fatigue. Frontiers in Immunology, 10, p. 1696. [DOI:10.3389/fimmu.2019.01696]

MacBeth, A. \& Gumley, A., 2012. Exploring compassion: A meta-analysis of the association between self-compassion and psychopathology. Clinical Psychology Review, 32(6), pp. 545-52. [DOI:10.1016/j.cpr.2012.06.003]

Maguire, R. \& Maguire, P., 2020. Caregiver burden in multiple sclerosis: Recent trends and future directions. Current Neurology and Neuroscience Reports, 20(7), p. 18. [DOI:10.1007/s11910 020-01043-5]

Meyer, U., 2019. Neurodevelopmental resilience and susceptibility to maternal immune activation. Trends in Neurosciences, 42(11), pp. 793-806. [DOI:10.1016/j.tins.2019.08.001]

Mirhosseini, S., et al. 2019. The effect of Benson relaxation technique on the fatigue severity of patients with MS. Journal of Client-Centered Nursing Care, 5(3), pp. 175-82. [DOI:10.32598/ JCCNC.5.3.175]

Moghadam, F., Ebrahimi Moghadam, H. \& Jahangir, P., 2021 The relationship between perfectionism, early maladaptive schemas, attachment styles, and body image concern by the mediating role of self-esteem in cosmetic surgery applicants. Journal of Client-Centered Nursing Care, 7(1), pp. 27-42 [DOI:10.32598/JCCNC.7.1.351.1]

Momeni, F., et al. 2014. [Psychometric properties of a Farsi version of the Self-Compassion Scale (SCS) (Persian)]. Contemporary Psychology, 8(2), pp. 27-40. http:/ / bjcp.ir/browse.php?a id $=386 \&$ sid $=1 \&$ slc_lang $=$ en 
Nabi, A., Ahmad, T. \& Khan, I., 2016. Hope and psychological well being among diabetes patients: A correlational study. International Journal of Indian Psychology, 3(4), pp. 2349-3429. [DOI:10.25215/0304.104]

Neff, K. D., 2003. Self-Compassion: An alternative conceptualization of a healthy attitude toward oneself. Self and Identity, 2(2), pp. 85-101. [DOI:10.1080/15298860309032]

Patten, S. B., 2020. Current perspectives on co-morbid depression and Multiple Sclerosis. Expert Review of Neurotherapeutics, 20(8), pp. 867-74. [DOI:10.1080/14737175.2020.1806062]

Pettit, T. J., Croxton, K. L. \& Fiksel, J., 2019. The evolution of resilience in supply chain management: A retrospective on ensuring supply chain resilience. Journal of Business Logistics, 40(1), pp. 56-65. [DOI:10.1111/jbl.12202]

Pourpashang, M. \& Mousavi, S., 2021. The effectiveness of group schema therapy on psychological well-being and resilience of the addicts under treatment. Journal of Client-Centered Nursing Care, 7(2), pp. 159-66. [DOI:10.32598/JCCNC.7.2.366.1]

Rezaei, M., et al. 2018. The impact of resilience on the perception of chronic diseases from older adults' perspective. Journal of Client-Centered Nursing Care, 4(4), pp. 231-9. [DOI:10.32598/ jccnc.4.4.231]

Rosi, A., et al. 2019. The impact of failures and successes on affect and self-esteem in young and older adults. Frontiers in Psychology, 10, p. 1795. [DOI:10.3389/fpsyg.2019.01795]

Rutten, B. P., et al. 2013. Resilience in mental health: Linking psychological and neurobiological perspectives. Acta Psychiatrica Scandinavica, 128(1), pp. 3-20. [DOI:10.1111/acps.12095]

Savari, K., Naseri, M. \& Savari, Y., 2021. Evaluating the role of perceived stress, social support, and resilience in predicting the quality of life among the parents of disabled children. International Journal of Disability, Development and Education, pp. 1-15. [DOI:10.1080/1034912X.2021.1901862]

Schaap, G. M., Chakhssi, F. \& Westerhof, G. J., 2016. Inpatient schema therapy for nonresponsive patients with personality pathology: Changes in symptomatic distress, schemas, schema modes, coping styles, experienced parenting styles, and mental well-being. Psychotherapy (Chicago, Ill.), 53(4), pp. 402-12. [DOI:10.1037/pst0000056]

Schmidt, S. \& Jöstingmeyer, P., 2019. Depression, fatigue and disability are independently associated with quality of life in patients with Multiple Sclerosis: Results of a cross-sectional study. Multiple Sclerosis and Related Disorders, 35, pp. 262-9. [DOI:10.1016/j.msard.2019.07.029]

Schroevers, M. J., Kraaij, V. \& Garnefski, N., 2011. Cancer patients' experience of positive and negative changes due to the illness: Relationships with psychological well-being, coping, and goal reengagement. Psycho-Oncology, 20(2), pp. 165-72. [DOI:10.1002/pon.1718]

Seiler, A. \& Jenewein, J., 2019. Resilience in cancer patients. Frontiers in Psychiatry, 10, p. 208. [DOI:10.3389/fpsyt.2019.00208]

Seyedoshohadaee, M., et al. 2016. The effects of life skills training on patients' adaptation with Multiple Sclerosis. Journal of Client-Centered Nursing Care, 2(4), pp. 215-22. [DOI:10.32598/ jccnc.2.4.2015]

Shahbazi, J., et al. 2020. Effects of mindfulness-based selfcompassion and attachment-based therapy on self-criticism and mental fatigue of male adolescents with addiction potential. Journal of Client-centered Nursing Care, 6(2), pp. 97-108. [DOI:10.32598/JCCNC.6.2.33.9]

Snyder, C. R., et al. 1996. Development and validation of the state hope scale. Journal of Personality and Social Psychology, 70(2), pp. 321-35. [DOI:10.1037/0022-3514.70.2.321]

Tabachnick, B. G. \& Fidell, L. S., 2007. Using multivariate statistics. $5^{\text {th }}$ ed. London: Pearson. https://books.google.com/ books?id=AkBlQgAACAAJ\&dq

Thoits, P. A., 2020. We know what they're going through: Social support from similar versus significant others. The Sociological Quarterly, pp. 1-22. [DOI:10.1080/00380253.2020.1802360]

Tugade, M. M. \& Fredrickson, B. L., 2004. Resilient individuals use positive emotions to bounce back from negative emotional experiences. Journal of Personality and Social Psychology, 86(2), pp. 320-33. [DOI:10.1037/0022-3514.86.2.320]

Van Dam, N. T., et al. 2011. Self-compassion is a better predictor than mindfulness of symptom severity and quality of life in mixed anxiety and depression. Journal of Anxiety Disorders, 25(1), pp. 123-30. [DOI:10.1016/j.janxdis.2010.08.011]

Veauthier, C. \& Paul, F., 2014. Sleep disorders in multiple sclerosis and their relationship to fatigue. Sleep Medicine, 15(1), pp. 5-14. [DOI:10.1016/j.sleep.2013.08.791]

Wong, D., Amon, K. L. \& Keep, M., 2019. Desire to belong affects Instagram behavior and perceived social support. $\mathrm{Cy}$ berpsychology, Behavior and Social Networking, 22(7), pp. 465-71. [DOI:10.1089/cyber.2018.0533]

Wong, S. T., et al. 2014. What type of social support influences self-reported physical and mental health among older women? Journal of Aging and Health, 26(4), pp. 663-78. [DOI:10.1177/0898264314527478]

Wongpakaran, T., Wongpakaran, N. \& Ruktrakul, R., 2011. Reliability and validity of the Multidimensional Scale of Perceived Social Support (MSPSS): Thai version. Clinical Practice and Epidemiology in Mental Health, 7, pp. 161-6. [DOI:10.2174/1745017 901107010161]

$\mathrm{Wu}, \mathrm{Y}$., et al. 2020. The relationship between resilience and mental health in Chinese college students: A longitudinal cross-lagged analysis. Frontiers in Psychology, 11, p. 108 [DOI:10.3389/fpsyg.2020.00108]

Zimet, G. D., et al. 1988. The multidimensional scale of perceived social support. Journal of Personality Assessment, 52(1), pp. 30-41. [DOI:10.1207/s15327752jpa5201_2] 
This Page Intentionally Left Blank 